\title{
Nasal NK/T cell lymphoma mimicking mucosa-associated lymphoid tissue lymphoma in morphology: A case report
}

\author{
GUOHUA YU ${ }^{1}$, XIAOQIAN LIU ${ }^{2}$, HUIHUI ZHOU ${ }^{1}$, LICAI AN ${ }^{2}$, HONGYAN LI ${ }^{1}$, \\ SHISHOU WU ${ }^{1}$, YINGHUI LIU ${ }^{2}$, XUBO PAN $^{1}$, GUIMEI QU ${ }^{1}$ and XIAOXIA CHU ${ }^{2}$ \\ Departments of ${ }^{1}$ Pathology and ${ }^{2}$ Hematology, Affiliated Yantai Yuhuangding Hospital, \\ Qingdao University, Yantai, Shandong 264000, P.R. China
}

Received February 24, 2019; Accepted June 28, 2019

DOI: $10.3892 / \mathrm{ol} .2019 .10865$

\begin{abstract}
The objective of the present study was to describe the clinicopathological features of a patient with nasal NK/T cell lymphoma that was similar in morphology to mucosa-associated lymphoid tissue lymphoma (MALToma). The clinicopathological data of a patient diagnosed with nasal NK/T cell lymphoma mimicking MALToma was collected, and the clinicopathological characteristics were discussed. The female patient was 43 years old and had suffered from persistent congestion for ten days. The mucosa in the left nasal cavity was inflamed, resulting in congestion and it was also purulent on the surface, as observed by nasal endoscopy. The disease was considered to be inflammatory based on CT scan. A biopsy after operation showed that the tumor consisted of small lymphoid cells that resembled MALToma in morphology. On the basis of the immunohistochemistry and in situ hybridization laboratory tests, a diagnosis of left nasal NK/T cell lymphoma was made. The patient received chemotherapy and radiotherapy, and remission was achieved six months after diagnosis. The patient was in a good condition at 16 months follow-up. In conclusion, NK/T cell lymphoma composed of small cells may be a type of indolent lymphoma with special characteristics of clinical presentation, image, pathology and prognosis. This case highlights that more attention is required by radiologists, pathologists and hematologists to diagnose this type of lymphoma.
\end{abstract}

Correspondence to: Dr Guimei Qu, Department of Pathology, Affiliated Yantai Yuhuangding Hospital, 20 Yuhuangding East Road, Qingdao University, Yantai, Shandong 264000, P.R. China E-mail: guimeiqu@126.com

Professor Xiaoxia Chu, Department of Hematology, Affiliated Yantai Yuhuangding Hospital, 20 Yuhuangding East Road, Qingdao University, Yantai, Shandong 264000, P.R. China

E-mail: lucychu126@126.com

Key words: NK/T cell lymphoma, nasal type, differential diagnosis, clinical stage

\section{Introduction}

$\mathrm{NK} / \mathrm{T}$ cell lymphoma is a type of aggressive non-Hodgkin lymphoma and mainly occurs in the extranodal organs with short survival time and poor response to therapy. It always occurs in adults at 44-54 years of age, and it is more common in males than in females. Asian and indigenous populations of Mexico, central and south of American have the highest incidence rates for this disease, which is associated with Epstein Barr virus infection (1,2). The nose is a common site for the development of this type of lymphoma; however, it can also develop in the skin, digestive tract, testis and lung $(3,4)$. Histologically, classical extranodal NK/T cell lymphoma includes the following morphological features: Neoplastic cells infiltrate diffusely, often invading and destroying the vascular wall, accompanied by massive tissue necrosis. Tumor cells vary in size, being primarily mixed with small-to-medium-sized lymphocytes. Large cells could often be observed in varying numbers and there are a large number of mixed inflammatory cells in the background. Immunohistochemical staining demonstrates that tumor cells usually express CD $3 \varepsilon$, CD56, Cytotoxic markers, such as Granzyme B, and TIA, while B cell markers have not been detected. Epstein Barr virus-Epstein Barr virus encoded RNA (EBV-EBER) is often detected via in situ hybridization staining (5-7). Mucosa-associated lymphoid tissue lymphoma (MALToma), which is different to NK/T cell lymphoma, is one kind of indolent B cell lymphoma with neoplastic cells of the same size. In the present study, a rare case of NK/T cell lymphoma with consistent small neoplastic cells resembling MALToma in histological morphology is reported. The specific clinical presentation, imaging and pathological data were retrospectively analyzed in order to investigate the clinicopathological characteristics of this type of lymphoma.

\section{Case report}

\section{Patient and methods}

Clinical data collection. In the present study, the case diagnosed as NK/T cell lymphoma in October 11, 2017 was obtained from the Department of Pathology, Yantai Yuhuangding Hospital (Shandong, China). Biopsy was taken via nasal endoscopy and the clinical data were obtained via 
CT scan, MRI scan, PET-CT scan, lumbar puncture, bone marrow biopsy, blood tests and follow-up.

Sample processing and morphological observation. The samples were immersed in $10 \%$ buffered formalin for complete fixation at room temperature after surgery. The ratio of fixative solution volume to tissue was 10:1, and fixation time was $12 \mathrm{~h}$. Subsequently, tissue dehydration and paraffin embedding were performed. Sections $4 \mu \mathrm{m}$ thick were cut from tissue blocks for hematoxylin and eosin staining at room temperature for $90 \mathrm{~min}$. Tissue morphology was observed under a light microscope (Olympus BX45; Olympus Corporation).

Immunohistochemical staining. EnVision two-step method was adopted using an automatic immunostainer (Ventana Medical Systems, Inc.) for immunohistochemical staining and subsequent DAB staining (DAB secondary antibody kit; Ventana Medical Systems Inc.). Endogenous peroxidase activity was removed by incubation with $0.3 \% \mathrm{H}_{2} \mathrm{O}_{2}$ for $4 \mathrm{~min}$ at $37^{\circ} \mathrm{C}$. The duration of incubations in primary and secondary antibodies was $32 \mathrm{~min}$ at $37^{\circ} \mathrm{C}$. Hematoxylin was used for counterstaining at room temperature for $1 \mathrm{~min}$, and each section was stained with known positive tissues as the positive control, while the negative control sample used PBS instead of primary antibody. The antibodies used in the current study were purchased from Beijing Zhongshan Jinqiao Biological Co. (Table I). SPN-9001 Histostain $^{\mathrm{TM}}$-SP kit was used as the secondary antibody (OriGene Technologies, Inc.). A microscope (Olympus B45) was used to assess the tissues, $2 \times 10,4 \times 10,10 \times 10,20 \times 10$ and 40x10 magnification.

In situ hybridization detection. Tissue sections were dewaxed, dehydrated and digested by proteinase $\mathrm{K}$ for $20 \mathrm{~min}$ at $37^{\circ} \mathrm{C}$. EBER probe hybridization solution $(100 \mathrm{ng} / \mathrm{ml})$ was added after the slice was dried using absolute ethanol and then incubation at $37^{\circ} \mathrm{C}$ for $30 \mathrm{~min}$. Tissues were incubated with horseradish peroxidase-labeled digoxin for $30 \mathrm{~min}$ at $37^{\circ} \mathrm{C}$; rinsed three times with PBS buffer for 2 min each time; rinsed with deionized water and $0.2 \mathrm{ml}$ DAB to each slide for $15 \mathrm{~min}$ in the dark. Epstein Barr virus probe was purchased from Beijing Zhongshan Jinqiao Biological Co., Ltd (Probe cat. no. A500P.9900; Probe sequence: 5'-CTCCTCCCTACCAAA ACCCTCACCACCCCC-3').

\section{Results}

Clinical data. A 43-year-old female patient suffered from persistent congestion in the left nasal cavity for ten days. The nasal congestion was persistent, and was accompanied by decreased olfactory sensation and purulent sputum. No improvement in symptoms was obtained with oral cephalosporin treatment, at which point the patient was referred to Yantai Yuhuangding Hospital. A physical examination gave the following measurements: Temperature, $36^{\circ} \mathrm{C}$; Pulse, 79 beats/min; Rate, 18 beats/min; blood pressure, 136/90 mmHg; Eastern Cooperative Oncology Group performance score, 0 ; and weight, $70.0 \mathrm{~kg}$. The nasal septum was in the middle. The mucosa inflamed, causing congestion, and was purulent on the surface in the left nasal cavity, as observed by nasal endoscopy (Fig. 1A). The nasal mucosa on the right side was smooth and no mass was observed. A CT scan identified obstruction, inflammatory lesions and granuloma formation in the left nasal cavity (Fig. 2A). MRI revealed that the mucosa was thickened in the left nasal cavity, and the lesion was considered to be inflammatory (Fig. 2B). Whole blood counts were as follows: White blood cells, 7.97x $10^{9} / 1$; red blood cells, $3.47 \times 10^{12} / 1$; hemoglobin, $102 \mathrm{~g} / \mathrm{l}$; Platelet, 363×10 $/ 1$; serum lactate dehydrogenase levels, $133 \mathrm{U} / \mathrm{l}$; and C-reactive protein level was normal. Blood tests for liver and renal function were normal. Peripheral blood EBV DNA copy number was $<3,000$ copies/ml. Positron Emission Tomography-CT (PET-CT) scan, lumbar puncture, bone marrow biopsy and aspiration did not show evidence of extra-nasal tumor metastasis. The patient received resection of left nasal mucosa and septum under endoscope in September 29, 2017.

Gross examination. The sample was obtained after surgery under nasal endoscopy. The gray and white tissue was irregular, and was $2.5 \times 2 \times 0.5 \mathrm{~cm}$ in size. The surface of some parts of the tissue was smooth.

Histological findings. Microscopically, the tissue was covered by pseudostratified ciliated columnar epithelium and intrinsic glands were atrophic. Monomorphic tumor cells of a small volume had infiltrated into the interstitial space (Fig. 3A). Under high magnification, the neoplastic cells showed slight dysplasia with unclear boundary and translucent or pink cytoplasm. The nuclei were small in size and slightly irregular in shape, with evenly distributed chromatin. The nucleolus was not obvious, and mitosis was observed occasionally (Fig. 3B). The epithelium of mucosal glands was invaded by tumor cells, and lymphoid epithelial lesions were found locally (Fig. 3C). Mitotic division was $\sim 3 / 10$ under high power field (light microscope, 40x10 magnification). No blood vessel invasion or coagulative necrosis were observed (Fig. 3D).

Immunohistochemical staining. Immunohistochemical staining showed tumor cells were positive for CD3, CD4, CD56, Bcl-2 and Granzyme $\mathrm{B}$, and the $\mathrm{Ki} 67$ positive rate was $<20 \%$. No expression of CD2, CD5, CD7, CD8, CD20, Cyclin D1, CD10, Bcl-6, CD23, Synaptophysin (Syn), Cytokeratin, Desmin and epithelial membrane antigen (EMA) was observed. Follicular dendritic cell network was not observed by CD21 staining and $5 \%$ of tumor cells expressed TP53 weakly (Fig. 4A-H).

In situ hybridization detection. A positive EBV-EBER signal was diffusely and consistently detected by in situ hybridization (Fig. 4I).

Diagnosis. On the basis of histological features, immunohistochemical staining and results of in situ hybridization, a diagnosis of left nasal NK/T cell lymphoma was made after ruling out other small cell neoplasm such as MALToma, Pseudomalignant NK-cell proliferation, Chronic active EBV infection of NK cells, Peripheral T cell lymphoma, small cell carcinoma, melanoma, embryonic rhabdomyosarcoma. This monomorphic type of NK/T cell lymphoma was rare, however special staining supported the diagnosis. As patient was young, 
Table I. Primary antibodies used in immunohistochemistry.

\begin{tabular}{lcc}
\hline Antibody & Catalog no. & Dilution \\
\hline Anti-CD2 & ZM-0278 & $1: 100$ \\
Anti-CD3 & ZM-0417 & $1: 100$ \\
Anti-CD4 & ZM-0418 & $1: 100$ \\
Anti-CD5 & ZM-0280 & $1: 100$ \\
Anti-CD7 & ZA-0589 & $1: 100$ \\
Anti-CD8 & ZA-0508 & $1: 100$ \\
Anti-CD56 & ZM-0057 & $1: 100$ \\
Anti-CD20 & ZA-0293 & $1: 100$ \\
Anti-BCL-2 & ZA-0536 & $1: 100$ \\
Anti-Granzyme B & ZA-0599 & $1: 100$ \\
Anti-Ki67 & ZM-0166 & $1: 100$ \\
Anti-cyclin D1 & ZM-0366 & $1: 200$ \\
Anti-BCL-6 & ZM-0011 & $1: 100$ \\
Anti-CD23 & ZM-0273 & $1: 100$ \\
Anti-CD10 & ZM-0283 & $1: 100$ \\
Anti-Synaptophysin & ZA-0263 & $1: 100$ \\
Anti-cytokeratin & ZM-0069 & $1: 100$ \\
Anti-Desmin & ZA-0610 & $1: 100$ \\
Anti-Epithelial membrane antigen & ZM-0095 & $1: 50$ \\
Anti-CD21 & ZM-0040 & $1: 100$ \\
Anti-TP53 & ZM-0408 & $1: 100$ \\
\hline
\end{tabular}

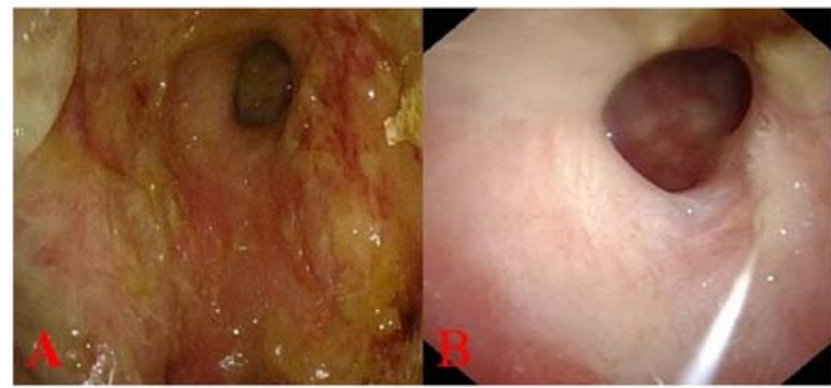

Figure 1. Comparison of mucosa changes in the left nasal cavity under endoscope (A) before treatment and (B) after treatment.

there was low proliferation of tumor cells and there was a lack of TP53 mutation, a good prognosis was expected.

Treatment and follow-up. The disease was classified as clinical stage IE, with a prognostic index for NK/T-cell lymphoma (PINK) score of 0 and PINK-EBV score of 0 after comprehensive evaluation. The patient received 'sandwich' chemoradiation. The chemotherapy regimen consisted of 3 cycles of intravenous GELOX regimen (gemcitabine, $1.2 \mathrm{~g} / \mathrm{m}^{2} \mathrm{~d} 1$, 8; oxaliplatin, $160 \mathrm{mg} / \mathrm{m}^{2} \mathrm{~d} 1$; pegaspargase, $3,200 \mathrm{IU} / \mathrm{m}^{2} \mathrm{~d} 3$, q21d) between October 19, 2017 and February 20, 2018. Nasopharynx radiotherapy was performed between December 11, 2017 and January 7, 2018 [planning target volume (PTV) 54 Gy/27 f] Two cycles of LOP chemotherapy program (pegaspargase, $3,200 \mathrm{IU} / \mathrm{m}^{2} \mathrm{~d} 1$; vindesine, $4 \mathrm{mg} / \mathrm{m}^{2} \mathrm{~d} 1$; dexamethasone, $\left.10 \mathrm{mg} / \mathrm{m}^{2} \mathrm{~d} 1-5\right)$ was adapted during radiotherapy. After radiotherapy, the patient received another cycle of GELOX for a

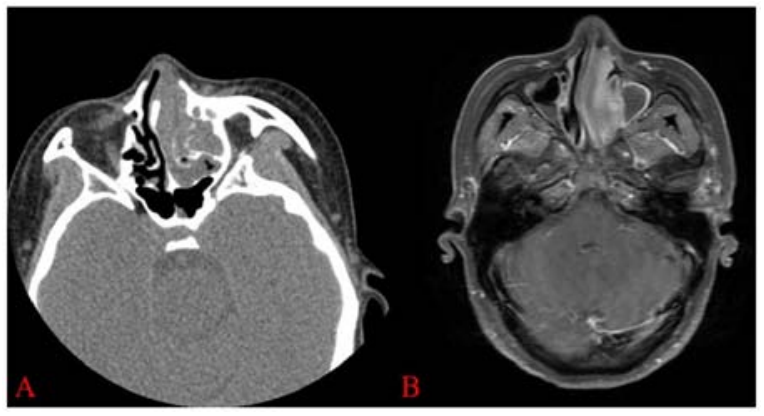

Figure 2. Imaging scans of the lesion. (A) Increased density was observed in the left nasal cavity and the left paranasal sinus by CT scan. No obvious damage was observed in the surrounding bone. (B) MRI scan showed visible enhancement in the front of the left nasal cavity, and a slightly longer $T_{1}$ and longer $\mathrm{T}_{2}$ signals could be detected in the left nasal cavity.

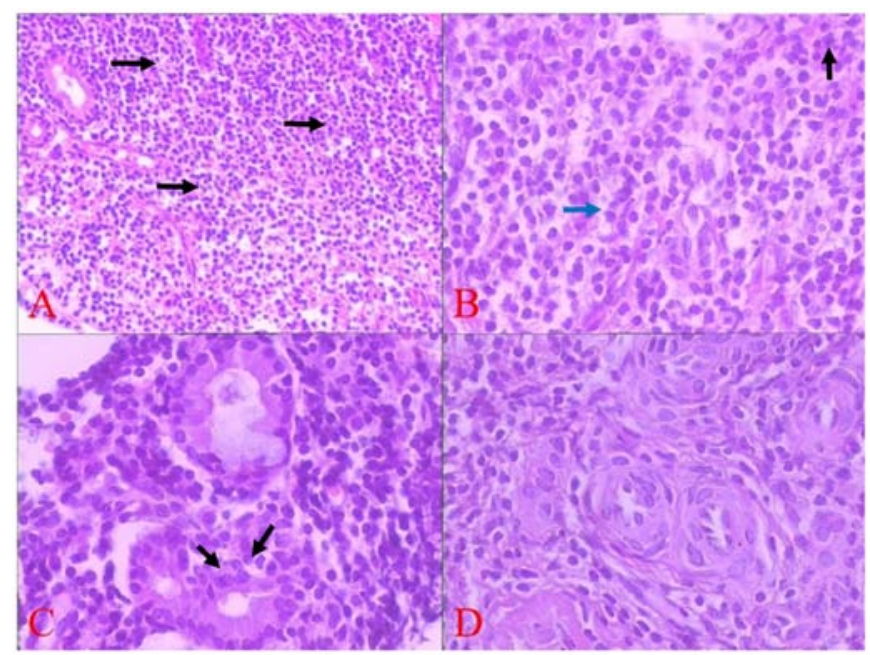

Figure 3. Histological morphology of NK/T cell lymphoma by hematoxylin and eosin staining. (A) Monomorphic tumor cells with small size infiltrated diffusely in the mucosal interstitial and inherent glands were atrophic (arrows showed consensus tumor cells in size, magnification x20). (B) Tumor cells with translucent or pink cytoplasm, slightly irregular nuclei and distributed chromatin (black arrow showed mitosis and blue arrow showed unclear boundary and translucent/pink cytoplasm, magnification $\mathrm{x} 40$ ). (C) Epithelium of mucosal glands was invaded by tumor cells (arrows showed epithelial lesions, magnification $\mathrm{x} 40$ ). (D) No blood vessel invasion and coagulation necrosis were observed (magnification $\mathrm{x} 20$ ).

total of 6 cycles of chemotherapy. The patient also received two lumbar intrathecal injections of cytarabine $\left(50 \mathrm{mg} / \mathrm{m}^{2}\right)$, dexamethasone $\left(5 \mathrm{mg} / \mathrm{m}^{2}\right)$ and methotrexate $\left(10 \mathrm{mg} / \mathrm{m}^{2}\right)$. All chemotherapy was done by intravenous. An endoscopy on March 26, 2018 revealed the left nasal mucosa was smooth (Fig. 1B), and PET-CT showed the metabolic value of the left nasal was lower than before (decrease from 2.1 to 4.3). No residual tumor cells were observed by mucosal biopsy. The response to therapy was complete remission. The patient was followed-up for 16 months after surgery, at which point she was in good condition with no relapse.

\section{Discussion}

Classical nasal NK/T cell lymphoma includes three main morphological characteristics: Pleomorphic tumor cells, vascular invasion and coagulation necrosis (8). The case 


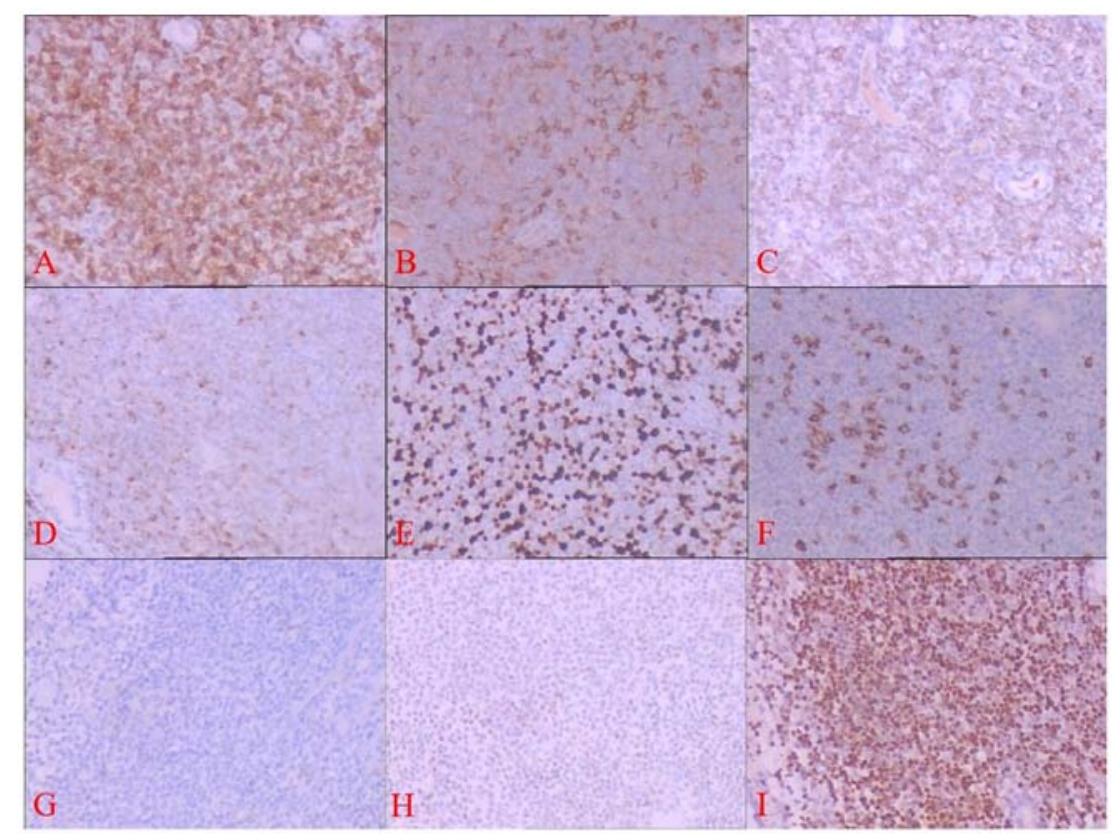

Figure 4. Immunohistochemical staining of the tumor. The tumor cells were positive for (A) CD3, (B) CD4, (C) CD56 and (D) Granzyme B. (E) Ki67 index was $<20 \%$. (F) Tumor cells were negative for CD20. (G) There was no follicular dendritic cell network by CD21 staining. (H) Mutant TP53 was expressed weakly in $5 \%$ of tumor cells. (I) Strong signal of EBV-EBER staining was observed by in situ hybridization (magnification x20).

described in the present study was unusual as it lacked the typical histological features mentioned above and presented with monomorphic features similar to MALToma. However, immunohistochemical markers and in situ hybridization staining results supported the diagnosis of NK/T cell lymphoma (9). A potential differential diagnosis is neoplasm showing monomorphic shape, which mimics MALToma, and should be ruled out. MALToma consists of small lymphoid cells with relatively uniform size, and lymphoid epithelial lesions and follicular implantation may also be present (10). MALToma expressed CD20, but not CD3, and the expression of restricted immunoglobulin light chain could be helpful for differential diagnosis with NK/T cell lymphoma (11). Pseudomalignant NK-cell proliferation is considered as a pseudomalignant disease because it spontaneously regresses without any treatment. The atypical cells in pseudomalignant NK-cell proliferation disease infiltrated diffusely and the glandular epithelium could be involved occasionally. These cells showed the immunophenotype that CD3, CD56 and cytotoxic molecule-associated proteins, such as Granzyme B, were usually positive which was similar with NK/T cell lymphoma. However, large eosinophilic cytoplasmic granules observed in pseudomalignant NK-cell proliferation and negative pattern of EBV-EBER were not consistent with NK/T-cell lymphoma (12). Chronic active EBV (CAEBV) infection of NK cells occurs most often in children and adolescents according to WHO classification (13). CAEBV has the following diagnostic criteria: Increased EBV DNA ( $>10^{2.5}$ copies $\left./ \mathrm{mg}\right)$ in peripheral blood; infectious mononucleosis-like symptoms persisting for $>3$ months; histological evidence of organ disease; and demonstration of EBV RNA or viral protein in affected tissues in patients without known immunodeficiency, malignancy or autoimmune disorders. The most common sites of CAEBV are bone marrow, lymph nodes, liver, spleen and skin (14). Although CAEBV and NK/T cell lymphoma both originate from NK cells, clinical presentation and laboratory tests distinguish the diseases from each other $(15,16)$. Peripheral $\mathrm{T}$ cell lymphoma also presents with small tumor cells that express markers of T lymphocytes such as CD2, CD3, CD4, CD5, CD7 and CD8, but negative expression of CD56, cytotoxic markers, and no EBV-EBER detection which could be helpful to differentiate it from NK/T cell lymphoma (17).

Tumor cells in small cell carcinoma have significant atypia, widespread mitosis and necrosis (18). Cytokeratin and neuroendocrine markers such as Syn and chromograninA are positively expressed in small cell carcinoma; however, these markers are negative in NK/T cell lymphoma (19). The nasal cavity is also a common site for malignant melanoma, which is aggressive and can result in destruction of the skull (20). Melanoma could also present with small cell in morphology. Positive expression of S-100, and melanoma markers, HMB45 and melan-A, can be used to distinguish melanoma from lymphoma (21). Embryonal rhabdomyosarcoma usually occurs in children and young adults. This type of tumor is composed of small cells with significant eosinophilic cytoplasm and deviated nuclei, showing 'tadpole-like' or 'racket-like' cells, with the nucleus towards one side of the cell (22). Myogenic markers such as Desmin and myogenin were positive in embryonal rhabdomyosarcoma, which could distinguish from NK/T cell lymphoma $(23,24)$.

The clinical features of the patient described in the present study were unusual. No clear mass was observed by nasal endoscopy, and only mucosal inflammation and purulent secretion were observed. Imaging studies lead to the misdiagnosis of chronic inflammation. Obtaining a biopsy earlier in the disease stage could be useful for early diagnosis. Mutant TP53 is considered to be an important protein for the progression of NK/T cell lymphoma (25-27). Previous studies on NK/T cell lymphoma in small cell types have not reported mutant TP53 $(9,28,29)$. In the present study, mutant TP53 was found 
to be expressed lowly in the tumor cells and $\sim 5 \%$ of tumor cells were weakly positive. Ki67 expression, a marker of cell proliferation, was $<20 \%$, which is much lower compared with Ki67 expression reported in NK/T cell lymphoma with classic morphology (30). Combining the clinical characteristics and laboratory results of this case, the conclusion was drawn that small cell type of NK/T cell lymphoma may be indolent.

Radiotherapy and chemotherapy are two main treatments for NK/T cell lymphoma (31); however, the prognosis of the majority of patients is poor (32). The patient in the present study received radiotherapy and chemotherapy. Complete remission was obtained after 6 months, and the patient achieved a good prognosis. This may be related to the early clinical stage at which the disease was diagnosed. The patient refused hematopoietic stem cell transplantation, and prognosis remains to be followed up in the future.

$\mathrm{NK} / \mathrm{T}$ cell lymphoma with small cell morphology is unusual, and may be a type of indolent lymphoma with particular characteristics of clinical presentation, imaging, pathology and prognosis. Early biopsy would aid in obtaining the correct diagnosis. More cases are required for further study, and attention should be paid to this kind of NK/T cell lymphoma by radiologists, pathologists and hematologists to prevent misdiagnosis in the future.

\section{Acknowledgements}

Not applicable.

\section{Funding}

The present study was supporting by the Yantai Key Research and Development Project (grant no. 2017WS101).

\section{Availability of data and materials}

The datasets used and/or analyzed during the present study are available from the corresponding author upon reasonable request.

\section{Authors' contributions}

GY designed the study, performed the histological evaluation and drafted the manuscript. XL, LA, HL, SW and YL were involved in the literature search and preparing of the material. $\mathrm{HZ}$ and XP performed the histological diagnosis and revised the manuscript. GQ and XC were involved in immunohistochemical evaluation and amending the manuscript. All authors read and approved the final manuscript.

\section{Ethics approval and consent to participate}

The present study was approved by the Yantai Yuhuangding Hospital Ethics Committee.

\section{Patient consent for publication}

Written informed consent was obtained from the patient for participation in the present study and for publication of this article.

\section{Competing interests}

The authors declare that they have no competing interests.

\section{References}

1. Yamaguchi M, Suzuki R and Oguchi M: Advances in the treatment of extranodal NK/T-cell lymphoma, nasal type. Blood 131: 2528-2540, 2018.

2. Chan JKC, Quintanilla-Martinez L and Ferry JA (eds): WHO classification of tumor of hematopoietic and lymphoid tissues (Revised 4th edition). IARC, Lyon, pp368-371, 2017.

3. Kang DH, Huh J, Lee JH, Jeong YK and Cha HJ: Gastrosplenic fistula occurring in lymphoma patients: Systematic review with a new case of extranodal NK/T-cell lymphoma. World J Gastroenterol 23: 6491-6499, 2017

4. Liang P, Ren XC and Gao JB: Radiological and clinical features of primary NK/T-cell lymphoma involving the whole length of the esophagus: A case report. Oncol Lett 14: 2147-2152, 2017.

5. Haverkos BM, Pan Z, Gru AA, Freud AG, Rabinovitch R, Xu-Welliver M, Otto B, Barrionuevo C, Baiocchi RA, Rochford R and Porcu P: Extranodal NK/T cell lymphoma, nasal type (ENKTL-NT): An update on epidemiology, clinical presentation, and natural history in North American and European cases. Curr Hematol Malig Rep 11: 514-527, 2016.

6. Tse E and Kwong YL: Diagnosis and management of extranodal NK/T cell lymphoma nasal type. Expert Rev Hematol 9: 861-871, 2016.

7. Zanelli M, Mengoli MC, Del Sordo R, Cagini A, De Marco L, Simonetti E, Martino G, Zizzo M and Ascani S: Intravascular NK/T-cell lymphoma, Epstein-Barr virus positive with multiorgan involvement: A clinical dilemma. BMC Cancer 18: 1115, 2018.

8. Sinkovics JG and Horvath JC: Human natural killer cells: A comprehensive review. Int J Oncol 27: 5-47, 2005.

9. Li S, Feng X, Li T, Zhang S, Zuo Z, Lin P, Konoplev S, Bueso-Ramos CE, Vega F, Medeiros LJ and Yin CC: Extranodal NK/T-cell lymphoma, nasal type: A report of 73 cases at MD Anderson cancer center. Am J Surg Pathol 37: 14-23, 2013.

10. Cook JR, Isaacson PG, Chott A, Nakamura $S$, Muller-Hermelink HK, Harris NL and Swerdlow SH (eds): WHO classification of tumor of hematopoietic and lymphoid tissues (Revised 4th edition). IARC, Lyon, pp259-262, 2017.

11. Coha B, Vucinic I, Mahovne I and Vukovic-Arar Z: Extranodal lymphomas of head and neck with emphasis on NK/T-cell lymphoma, nasal type. J Craniomaxillofac Surg 42: 149-152, 2014.

12. Takeuchi K, Yokoyama M, Ishizawa S, Terui Y, Nomura K, Marutsuka K, Nunomura M, Fukushima N, Yagyuu T, Nakamine H, et al: Lymphomatoid gastropathy: A distinct clinicopathologic entity of self-limited pseudomalignant NK-cell proliferation. Blood 116: 5631-5637, 2010.

13. Swerdlow SH, Campo E, Harris NL, Jaffe ES, Pileri SA, Stein H, Thiele J, Arber DA, Hasserjian RP, Le Beau MM, (eds), et al: WHO classification of tumours of hematopoietic and lymphoid tissues, revised 4th edition. IARC, Lyon, 2017.

14. Kimura $\mathrm{H}$ and Cohen JI: Chronic active Epstein-Barr virus disease. Front Immunol 8: 1867, 2017.

15. Hu LM, Takata K, Miyata-Takata T, Asano N, Takahashi E, Furukawa K, Miyoshi H, Satou A, Kohno K, Kosugi H, et al: Clinicopathological analysis of 12 patients with Epstein-Barr virus-positive primary intestinal T/natural killer-cell lymphoma $\left(\mathrm{EBV}^{+}\right.$ITNKL). Histopathology 70: 1052-1063, 2017.

16. Kimura H: EBV in T-/NK-cell tumorigenesis. Adv Exp Med Biol 1045: 459-475, 2018.

17. Uemura Y, Isobe Y, Uchida A, Asano J, Nishio Y, Sakai H, Hoshikawa M, Takagi M, Nakamura N and Miura I: Expression of activating natural killer-cell receptors is a hallmark of the innate-like T-cell neoplasm in peripheral T-cell lymphomas. Cancer Sci 109: 1254-1262, 2018.

18. Hourdequin KC, Lefferts JA, Brennick JB, Ernstoff MS, Tsongalis GJ and Pipas JM: Merkel cell polyomavirus and extrapulmonary small cell carcinoma. Oncol Lett 6: 1049-1052, 2013.

19. Ding W, Wang J, Zhao S, Yang Q, Sun H, Yan J, Gao L, Yao W, Zhang W and Liu W: Clinicopathological study of pulmonary extranodal nature killer/T-cell lymphoma, nasal type and literature review. Pathol Res Pract 211: 544-549, 2015. 
20. Ganti A, Raman A, Shay A, Kuhar HN, Auger SR, Patel T, Kuan EC, Diaz AZ, Batra PS and Tajudeen BA: Treatment modalities in sinonasal mucosal melanoma: A national cancer database analysis. Laryngoscope, Apr 25, 2019 (Epub ahead of print).

21. Bourne TD, Bellizzi AM, Stelow EB, Loy AH, Levine PA, Wick MR and Mills SE: p63 Expression in olfactory neuroblastoma and other small cell tumors of the sinonasal tract. Am J Clin Pathol 130: 213-218, 2008.

22. Wu Y, Li C, Zhong Y, Guo W and Ren G: Head and neck rhabdomyosarcoma in adults. J Craniofac Surg 25: 922-925, 2014

23. Jiménez-Heffernan JA, González-Peramato P, Perna C, Alvarez-Ferreira J, López-Ferrer P and Viguer JM: Fine-needle aspiration cytology of extranodal natural killer/T-cell lymphoma. Diagn Cytopathol 27: 371-374, 2002.

24. Wooff JC, Weinreb I, Perez-Ordonez B, Magee JF and Bullock MJ: Calretinin staining facilitates differentiation of olfactory neuroblastoma from other small round blue cell tumors in the sinonasal tract. Am J Surg Pathol 35: 1786-1793, 2011.

25. Aozasa K, Takakuwa T,Hongyo T and Yang WI: Nasal NK/T-cell lymphoma: Epidemiology and pathogenesis. Int J Hematol 87: 110-117, 2008

26. Huang HS, Liao CK, Liu TT, You HL, Wang MC and Huang WT: TP53 mutations in peripheral mature T and NK cell lymphomas: A whole-exome sequencing study with correlation to p53 expression. Hum Pathol 80: 145-151, 2018.
27. Zhou J, Zhang C, Sui X, Cao S, Tang F, Sun S, Wang S and Chen B: Histone deacetylase inhibitor chidamide induces growth inhibition and apoptosis in NK/T lymphoma cells through ATM-Chk2-p53-p21 signalling pathway. Invest New Drugs 36: 571-580, 2018.

28. Kuo TT, Shih LY and Tsang NM: Nasal NK/T cell lymphoma in Taiwan: A clinicopathologic study of 22 cases, with analysis of histologic subtypes, Epstein-Barr virus LMP-1 gene association, and treatment modalities. Int J Surg Pathol 12: 375-387, 2004.

29. McKelvie PA, Climent F, Krings G, Hasserjian RP, Abramson JS, Pilch BZ, Harris NL, Ferry JA, Zukerberg LR and Sohani AR: Small-cell predominant extranodal NK/T cell lymphoma, nasal type: Clinicopathological analysis of a series of cases diagnosed in a Western population. Histopathology 69: 667-679, 2016.

30. $\mathrm{Au} \mathrm{WY}$, Weisenburger DD, Intragumtornchai T, Nakamura S, Kim WS, Sng I, Vose J, Armitage JO and Liang R; International Peripheral T-Cell Lymphoma Project: Clinical differences between nasal and extranasal natural killer/T-cell lymphoma: A study of 136 cases from the International peripheral T-Cell lymphoma project. Blood 113: 3931-3937, 2009.

31. Moon JH, Lee BH, Kim JA, Lee YJ, Chae YS, Yhim HY, Kwak JY, Do YR, Park Y, Song MK, et al: Clinical impact of induction treatment modalities and optimal timing of radiotherapy for the treatment of limited-stage NK/T cell lymphoma. Leuk Res 49: 80-87, 2016.

32. Yamaguchi $\mathrm{M}$ and Miyazaki K: Current treatment approaches for NK/T-cell lymphoma. J Clin Exp Hematop 57: 98-108, 2017. 